\title{
APRESENTAÇÁO
}

\section{RIGOR PROFISSIONAL E SENSO DE PARTILHA: A TRAJETÓRIA EXEMPLAR DE MARIA DA GLÓRIA BORDINI}

Existe um traço peculiar ao conjunto da carreira de Maria da Glória Bordini: o cuidado de aliar teoria e prática como fator extensivo a diferentes níveis de competência acadêmica. A esse traço geral, podemos somar o que facilmente cabe na conta de preocupaçáo temática constante. Trata-se de sua dedicação continuada à obra de Erico Verissimo. Traduzida em páginas, estas se contam às centenas.

Ao modo de aproximar crítica e prática social, assumiu em 1982 e, exemplarmente, neste caso -, a coordenação do Acervo Literário Erico Verissimo, coleção atualmente sediada no Instituto Moreira Salles, no Rio de Janeiro. Os textos decorrentes do exercício de sistematizar documentos, correspondências, versóes originais e imagens têm ajudado a ampliar uma verdadeira política de preservação documental do passado em diversas instituiçôes brasileiras. Sem contar que o processo voltado a destrinchar a ficção de Verissimo significa, ele próprio, contribuição que se alinha à melhor crítica especializada.

Rigorosa e detalhista, é nesses termos que Maria da Glória Bordini traduz sistematicamente as funçóes usuais de sua atividade em forma de reflexôes e sistematizaçóes que contribuem para multiplicar e socializar o saber. Eis o que a torna modelo de cidadá, intelectual, escritora e professora. Ela não circunscreve seu ofício aos domínios de interesses pessoais ou circunstanciais. Ao contrário, estende-o sob a dinâmica de um moto contínuo de transferências mútuas entre o pensar e o agir.

Sua iniciação acadêmica foi, a um tempo, relevante e conturbada. Relevante, pela base sólida da formação; conturbada, pelas dificuldades impostas em época de crise político-institucional. Formada em Letras pela Universidade Federal do Rio Grande do Sul no final da década de 1960, encontrou em nomes referenciais como Angelo Ricci, Gerd Bornheim e Dionísio de Oliveira Toledo os exemplos que cedo consolidaram uma preocupação que, no interesse profissional pela literatura, exprimiu eficazmente a relação teoria e prática. Seguiu-se a essa ascendência das mais promissoras, o incidente da cassaçáo pelo AI-5. Ainda em início de carreira e vetada ao exercício em instituição pública de qualquer natureza, amargurou 
a incerteza do futuro. Socorreram-lhe colegas e amigos, avalistas de sua fértil competência. Transferiu-se para a iniciativa privada, até recompor o elo perdido com a academia, o que o fez, nos anos 80, através de trabalho de mestrado e de função docente que conquistou na Pontifícia Universidade Católica - sempre em Porto Alegre.

Em Fenomenologia e Teoria Literária, livro de 1990 e resultado do trabalho de dissertação, explicita os termos de seu interesse por uma visão que ultrapassa o estrito domínio conceitual, de caráter formalista. Afirmava a autora: "uma das questôes centrais da teoria da literatura está na relação da obra com a realidade, que por sua vez implica a da linguagem com o mundo" (BORDINI, 1990, p. 15).

Para dar conta de intrincado problema teórico-filosófico e de metodologia, recorria a Edmund Husserl, mestre do método fenomenológico que lera sob a esclarecida tutela do citado Gerd Bornheim, amigo e mestre dos tempos de UFRGS, e de Jayme Paviani, seu contemporâneo de PUCRS. E, pelas sugestóes encontradas em Husserl, chegava a Roman Ingarden, caminho que lhe permitia rever o método a favor do entendimento de que a totalidade de uma obra de arte é composta de camadas heterogêneas.

Antes e depois do ensaio dedicado à fenomenologia que, por assim dizer, dá estofo conceitual ao conjunto expressivo de suas atividades, as aludidas funçóes fora dos bancos universitários sedimentaram-lhe as dimensôes de criar e de fazer circular livros como veículos da matéria literária. Foi o caso do período entre 1969 e 1980, quando se dedicou a atividades na Editora Globo, em boa parte do tempo, exercendo o cargo de Secretária Editorial. Também foi o caso do interregno que vai de 81 a 90, quando dirigiu as coleçôes infanto-juvenis da L\&PM Editores. Nesse último registro, a atividade já decorreu diretamente do trabalho com o filáo literário que ajudou a implantar na PUCRS, abrindo caminho para pesquisas sobre leitura e literatura infantil que, a partir daquele momento, ganharam um foro ainda desconhecido da universidade brasileira.

$\mathrm{Na}$ PUCRS - e mais uma vez através da produtiva junção entre teoria e prática -, Maria da Glória participou decisivamente da criaçáo do Centro de Memória Literária. O trabalho com o espólio de Erico Verissimo permitiu-lhe modelar um sistema de gestáo, que, de acordo com o seu próprio testemunho, criou a possibilidade de uma nova área de pesquisa:

Tratamos [o grupo da PUCRS, na época sob coordenação de Regina Zilberman] não só de preservar os documentos, mas de difundir a memória literária dos autores, o que tornou nossa atividade reconhecida não só na 
comunidade local, mas em todo o Brasil. Foi assim que, ao lançarmos a ideia dos Encontros Nacionais de Acervos Literários Brasileiros, houve franca acolhida de todos os centros de documentação do País, não só os interessados em literatura, e foi possível produzir e ampliar o conhecimento nesse campo, que ultrapassava o meramente arquivístico até então vigente (entrevista concedida pela autora e publicada neste número da Fragmentum).

Essa materialidade objetiva dos projetos de Maria da Glória continua atualmente refletida em sua produçáo textual. É o que se constata no exame dos objetivos que tem perseguido nos últimos anos. $\mathrm{O}$ seu olhar atento e empenhado vem encontrando no recorte social da ficção, através da interação obra e experiência biográfica, um rico filăo para o juízo crítico contemporâneo. São os casos de suas investigaçôes sobre o testemunho de Erico Verissimo e de sua obra, primeiro sob a poética da cidade e, mais recentemente, na perspectiva de materiais e livros de viagem. Nesse aspecto, seu ensinamento é de que as informaçóes documentais, sob a forma de cartas, relatórios, entrevistas, discursos oficiais, reportagens, críticas, livros consultados, evidências de intertextualidade e de produçáo editorial e gráfica, bem como dados mercadológicos, articulam-se ao abrigo do tema da narrativa de viagem e da residência no estrangeiro. Avulta, nesse contexto, o exame de aspectos da vida social, histórica e cultural dos Estados Unidos sob a lente de um ficcionista que também foi professor-visitante naquele país e dirigiu, em Washington, o Departamento Cultural da União PanAmericana, hoje Organização dos Estados Americanos.

Da dedicação à obra de Verissimo decorrem alguns de seus títulos mais destacados que, junto com o aludido Fenomenologia e Teoria Literária, compóem referências entre especialistas e não especialistas do campo dos estudos literários. São os casos de Criaçáo Literária em Erico Verissimo (1995) e Poética da cidade em Erico Verissimo (2012). A esses somam-se dezenas de publicaçôes em forma de artigos em periódicos, livros completos e capítulos assinalados pelos principais objetos de interesse que têm pautado sua pesquisa, como história e identidade em expressóes literárias de língua portuguesa, leitura e formação de leitor, história da literatura, estética e poética.

Reconhecida pela excelência de sua prática docente em sala de aula e pelo trabalho seguro de orientação na pós-graduação (de acordo com informaçóes constantes na Plataforma Lattes, desde a década de 1990, são quatro dezenas de dissertaçôes de mestrado e mais de duas dezenas de orientaçóes de doutorado concluídas), atualmente, como aposentada, desempenha as funçóes de professora colaboradora da UFRGS. 
Referindo-se uma vez ao modo de incorporar com excessiva rapidez as correntes teóricas, frequente nas instituiçóes de ensino superior do Brasil, Roberto Schwarz sentenciou que o universalismo infuso da teoria literária, em parte, não decorre dela, mas "da sua adoção acrítica noutras plagas [que] cancela a construção intelectual da experiência histórica em curso" (SCHWARZ, 1999, p. 84). Compromissada com as exigências concretas do seu tempo e com o rigor conceitual de um saber atualizado na forma de problema concreto de pesquisa, Maria da Glória pontua uma trajetória voltada a contradizer aquela prática denunciada por Schwarz, porque, com ela, a tradição teórica e metodológica cumpre função precípua de dialogar com os objetos pesquisados. De acordo com as próprias palavras de nossa professora: "As teorias, desconcertantemente, não são estáveis, mas suas vigências permanecem enquanto produzem interpretaçóes aceitáveis" (BORDINI, entrevista concedida pela autora e publicada neste número da Fragmentum).

Este número da Fragmentum é, pois, dedicado a Maria da Glória Bordini, querida amiga e mestra. $\mathrm{Na}$ sequência, dispusemos, inicialmente, um breve depoimento do professor Orlando Fonseca, cuja tese de doutoramento na PUCRS foi desenvolvida sob a orientaçáo de nossa homenageada. Segue-se uma entrevista, que aborda, de maneira sintética e direta, aspectos relevantes da trajetória de Maria da Glória. O artigo que vem após é ilustrativo do citado interesse permanente pelo conjunto da obra de Erico Verissimo. Trata-se de mostrar a transfiguração ficcional que o autor operou, ao longo de seu projeto literário, das principais catástrofes históricas de seu tempo. Por fim, na listagem das publicaçôes que tem assinalado a carreira de Maria da Glória, uma clara amostra dos principais campos de interesse que lhe têm movido o espírito crítico e que atrás destacamos.

Esperamos, com esta "juntada”, expressar aspectos relevantes da presença intelectual de Maria da Glória Bordini, orgulho para todos nós. Uma presença inquieta, empenhada e exemplar. E que, da posição de pesquisadora de escol que, com justiça, alcançou, continua a ver na sala de aula o espaço privilegiado do saber partilhado e transformador. Como ela mesma nos conta e ensina: "meus alunos me obrigam a estudar sempre, a propor novas temáticas e abordagens e isso é o grande prazer de ser professor - além do que nos divertimos bastante" (BORDINI, entrevista concedida pela autora e publicada neste número da Fragmentum). 


\section{Referências}

BORDINI, Maria da Glória. Fenomenologia e teoria literária. São Paulo: EDUSP, 1990.

SCHWARZ, Roberto. Os sete fôlegos de um livro. In: AGUIAR, Flavio (Org.). Pensamento e militância. São Paulo: Fundação Perseu Abramo; Humanitas, 1999. 